\title{
O VÍDEO COMO RECURSO DIDÁTICO NO ENSINO DE QUÍMICA
}

\author{
Adriana Watanabe - Universidade Cruzeiro do Sul - a.watanabe@uol.com.br \\ Tatiane Baldoria - Universidade Cruzeiro do Sul - baldoria.t@ gmail.com \\ Carmem Lucia Costa Amaral - Universidade Cruzeiro do Sul - \\ camem.amaral@cruzeirodosul.edu.br
}

\begin{abstract}
Resumo
O presente trabalho descreve um relato de experiência utilizando a produção de um vídeo pelos alunos como recurso didático para o ensino de química com o objetivo de predispor o aluno à aprendizagem significativa de oxirredução. O vídeo foi desenvolvido por 45 alunos do Curso Técnico em Química de uma escola técnica pública situada na cidade de São Paulo. Para o seu desenvolvimento foi solicitado alguns itens como conceito, reações, aplicação de um exercício com correção e a realização de um experimento utilizando materiais alternativos. Após a produção do vídeo, os alunos socializaram suas produções com os colegas e responderam um questionário avaliando o vídeo como ferramenta para a sua aprendizagem. Os resultados evidenciaram que a construção do vídeo motivou os alunos a estudarem e, consequentemente contribuiu para a aprendizagem significativa do conhecimento de oxirredução.
\end{abstract}

Palavras-chave: Ensino de química. Oxirredução. Produção de vídeo.

\section{THE VIDEO AS DIDACTIC RESOURSE IN THE TEACHING OF CHEMISTRY}

\begin{abstract}
The present work describes a report of an experiment using the production of a video by the students as a didactic tool to the chemistry teaching with the objective of incline the student to a significant learning redox reaction. The video was developed by forty five students from the technical course in Chemistry from a public technical school located in São Paulo city. For its development it was asked some items as concept, reaction, application of an exercise about the subject with correction and the realization of an experiment using alternative materials. After the video production, the students socialized their productions with their colleagues and answered a survey evaluating the video as a tool for their learning. The results showed that the construction of the video motivated the students to study and, hence contributed to the significant learning of the redox reaction knowledge.
\end{abstract}

Keywords: Chemistry teaching. Redox Reaction. Video Production. 


\section{1-INTRODUÇÃO}

Reações de oxirredução são aquelas que envolvem transferência de elétrons de uma espécie para outra. Nessas reações, a espécie que doa seus elétrons se oxida e a que recebe elétrons se reduz. Esse processo ocorre simultaneamente e por isso são chamadas de reações de oxirredução.

O exemplo mais comum é o da corrosão metálica que é o resultado da reação de oxidação do ferro pelo oxigênio (que se reduz) em meio aquoso. A corrosão é uma forma de degradação do metal ferro que progride até sua destruição total. Assim, estudar o processo de corrosão é importante do ponto de vista industrial e ambiental, uma vez que afeta a durabilidade das estruturas e peças metálicas, construções e monumentos etc.

Além desse processo de corrosão, para Moore (2010), as reações de oxirredução estão presentes em diversas outras situações de nosso dia a dia como na respiração, fotossíntese e nas pilhas e baterias usadas para gerar energia. $O$ estudo desse tipo de reação abre um vasto campo de pesquisas com grande valor para a química industrial, bioquímica, eletroquímica entre outras áreas.

Esse conteúdo é estudado na maioria das escolas de nível médio, como o Ensino Médio e Ensino Técnico. Para este último, o conhecimento desse conteúdo é imprescindível uma vez que como descreve Oliveira (2012, p.9) "nesse século XXI, o mercado de trabalho exige reflexões sobre responsabilidade social, responsabilidades técnicas seguidas de avaliações sobre as consequências causadas pelos materiais em processo corrosivo".

Como professoras de Química para esse nível de ensino percebemos que a maioria dos nossos alunos apresentam dificuldades em sua aprendizagem, principalmente a partir de um ensino tradicional, onde os conceitos são apresentados de forma não contextualizada e como consequência, os alunos mostram desmotivados e desinteressados em aprender esse conteúdo.

Pensando em auxiliar o aluno não só na aprendizagem potencialmente significativa de conteúdos de oxirredução, mas também motivá-lo a aprender, ou seja, torná-lo ativo e responsável pela sua aprendizagem, propomos em nossas aulas a construção de um vídeo por eles como recurso didático. Desta forma, o objetivo desse trabalho é relatar sobre os resultados dessa construção na aprendizagem potencialmente significativa dos nossos alunos.

\section{2- O VÍDEO NA SALA DE AULA}

As Tecnologias da Informação e Comunicação (TIC) estão cada vez mais presentes em nossa sociedade e vem modificando a estrutura da escola. As TIC podem ser compreendidas como um conjunto de recursos tecnológicos que proporcionam a comunicação e a informação. Entre esses recursos tem-se as câmeras de vídeos, internet, celulares, correio eletrônico (e-mail), objetos de aprendizagem, entre outros (NAPOLITANO, 2004).

Com todos esses recursos, a geração atual pode aprender os conteúdos escolares de forma interativa, divertida e dinâmica, e como descrevem Amaral e Amaral (2008) a escola deve aproveitar esses recursos para modernizar suas práticas e propostas de ensino e aprendizagem para atender às novas necessidades impostas pelo mundo dinâmico e globalizado. 
Quanto ao uso desses recursos, Costa (2014) descreve que o desafio do professor é saber utilizá-los em sala de aula. Para este autor, um dos recursos das TIC mais difundido entre os professores é o vídeo, que além de tornar a aprendizagem mais dinâmica, pode ser um canal eficiente de discussões e debates.

De acordo com Lima (2001) esse recurso foi introduzido nas escolas brasileiras na década de 1980, e se consolidou como recurso pedagógico a partir da década de 1990 com a implementação da TV Escola pelo Ministério da Educação que tem como objetivo capacitar, aperfeiçoar e atualizar professores da rede pública desde 1996.

Para Moran (2009) o vídeo auxilia no processo de ensino e aprendizagem pela sua dinâmica e sua linguagem que facilitam o caminho para níveis de compreensão mais complexos, mais abstratos, com menos apoio sensorial como os textos filosóficos. Podem ser utilizados em sala de aula para motivar os alunos, como vídeo aulas, como produção individual ou coletiva, para registro de eventos, de aulas, de estudo do meio, de experiências, de entrevistas, depoimentos e avaliação.

Nesse trabalho o vídeo foi utilizado como recurso didático com o objetivo de predispor o aluno a aprender de forma significativa, pois de acordo com Moreira (2012) este é um dos requisitos para uma aprendizagem significativa.

As finalidades descritas acima por Moran (2009) mostram que há vários tipos de vídeos que podem ser utilizados nas escolas. Entretanto, ao realizar uma pesquisa com professores de Ciências, Passou et al. (2011) constataram que esses professores preferem o gênero documentário, por ser mais fácil para fazer a conexão com o conteúdo, pois este é "a enunciação da verdade", portanto leva a possibilidade de se aprender.

Para Santos e Alves (2006) a prática do uso do vídeo como ferramenta pedagógica possibilita capturar comportamentos verbais como a fala e comportamento não verbal como os gestos e expressões dos alunos. Permite aos pesquisadores ver e rever as cenas quantas vezes forem necessárias.

No Ensino de Química, os discentes podem a partir do vídeo observar e analisar simulações de experimentos. Na ausência de um laboratório ou na falta de reagentes esse recurso didático complementa a aula teórica, estimula a participação do aprendiz e o seu desenvolvimento cognitivo. Segundo Silva et al. (2012):

o vídeo traz uma forma multilinguística de superposição de códigos e significações, predominantemente audiovisuais, apoiada no discurso verbal-escrito, partindo do concreto, do visível, do imediato. A linguagem audiovisual desenvolve múltiplas atitudes perceptivas, pois solicita constantemente a imaginação (SILVA et al., 2012, p.190).

As atitudes perceptivas descritas acima por Silva et al. (2012) facilitam a aprendizagem quando o aluno é o protagonista do vídeo, participando de todas as suas etapas, desde a concepção da ideia até a edição das gravações.

Essa é uma atividade que a princípio não é difícil de ser realizada, uma vez que grande parte dos adolescentes dessa geração tem acesso ao celular que possui câmera e internet. Desse modo, colocá-lo como protagonista do seu conhecimento a partir da produção do vídeo é dar-lhe autonomia, orientação e motivação para aprender.

Moran (2009) cita alguns benefícios que a produção de vídeo pelos alunos pode trazer a sua aprendizagem. Entre esses benefícios estão: aulas mais atraentes, uma vez que a sua produção estimula a participação e as discussões; desenvolvimento da criatividade, auxilia na comunicação e interação com seus colegas de classe e melhora a fixação do conteúdo. 
O vídeo mescla diversas linguagens que podem se transformar em atividades desafiadoras e instigantes para os alunos. Saber selecionar informações, gravar e produzir vídeos são atividades que podem contribuir para tirar o aluno do seu papel passivo, motivando-o a apender.

\section{3- METODOLOGIA}

Essa experiência foi desenvolvida com 45 alunos de uma Escola Técnica da cidade de São Paulo. Os vídeos foram construídos por eles como uma atividade para a disciplina "Tecnologia dos Materiais Inorgânicos".

Antes de propor a construção do vídeo pelos alunos foi elaborado um questionário com 4 perguntas com o intuito analisar se eles assistiam vídeos e quais suas preferências: Você gosta de assistir vídeos? Qual (is) o(s) tipo(s) de vídeo(s) você gosta de assistir? Você já produziu algum vídeo? Você acredita no vídeo como uma ferramenta para aprender?

A partir da resposta dessas questões foi proposto aos alunos que produzissem um vídeo com a temática oxirredução. Esse vídeo deveria apresentar conceitos, exercícios e um experimento com materiais alternativos. Os alunos foram divididos em grupos e os vídeos foram produzidos em seus celulares durante um tempo de três semanas e no final todos apresentaram suas produções para a classe.

Embora essa construção tenha ocorrido como atividade extraclasse, durante as aulas presenciais, os grupos tiravam dúvidas com as professoras.

Para a avaliação dos vídeos utilizamos como critérios a organização na apresentação e compreensão do conteúdo, clareza de comunicação e explicação do fenômeno de oxirredução. Em relação a proposta do experimento os critérios de avaliação foram: o uso adequado do material escolhido, o desempenho no desenvolvimento do experimento e a interpretação das observações.

Após o término da construção e apresentação do vídeo, os alunos avaliaram essa atividade respondendo a questão: Qual é a sua opinião sobre esta atividade?

\section{4- RESULTADOS E DISCUSSÃO}

Como citado anteriormente, antes da construção do vídeo os alunos responderam um questionário com quatro questões. As duas primeiras questionavam se eles assistiam vídeos e qual seu tipo preferido. Quanto a essas questões, todos responderam que assistiam vídeos e os tipos que gostavam de assistir variaram, sendo seus preferidos os seriados, seguidos de novelas e filmes como pode ser observado no gráfico 1. 

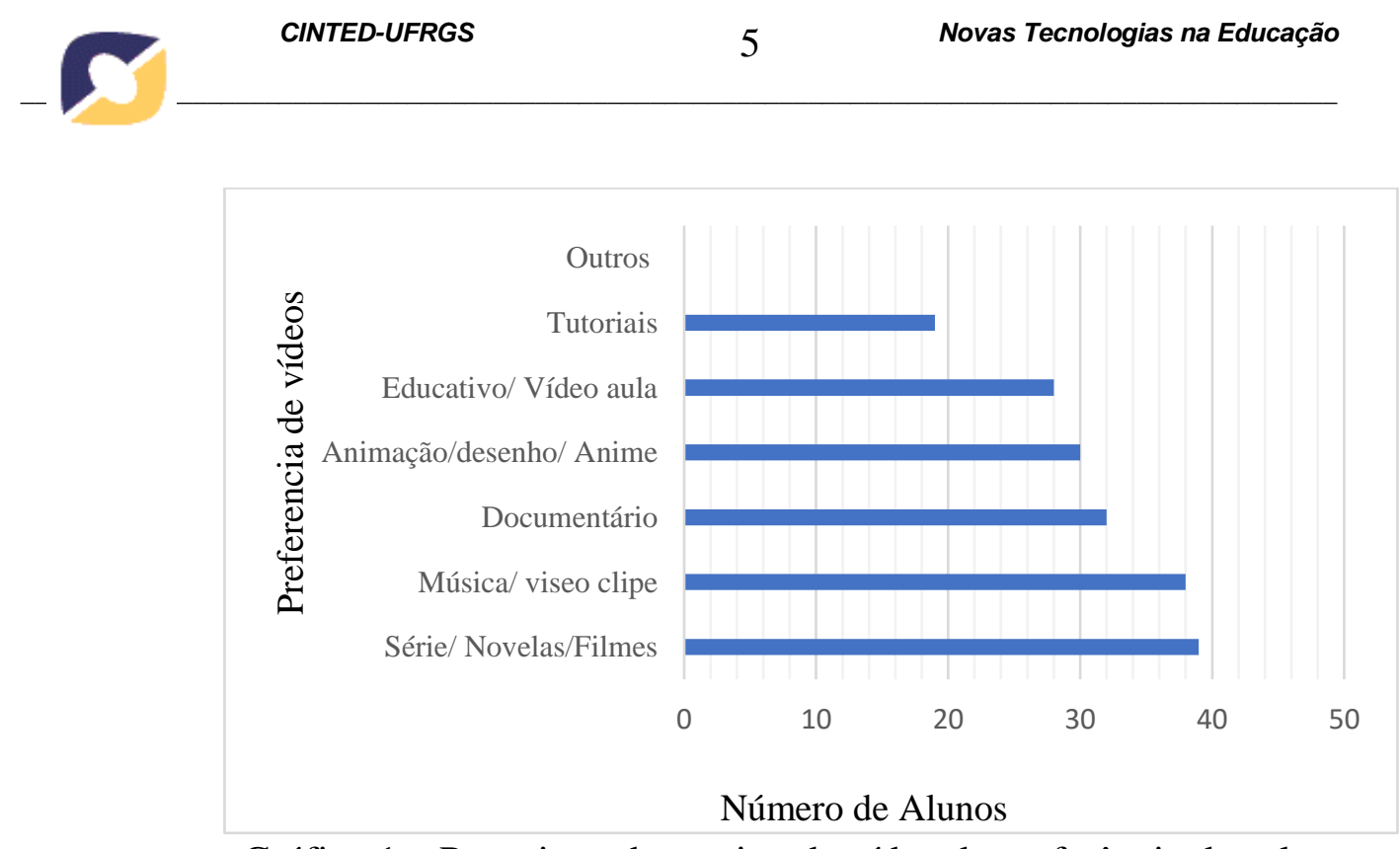

Gráfico 1 - Pesquisa sobre o tipo de vídeo de preferência dos alunos. Fonte: As autoras

Essas respostas não foram surpresas, pois como sabemos, atualmente o número de adolescentes que assistem vídeos é grande e o local preferido é o canal do YouTube. De acordo com o relatório YouTube Insights ${ }^{1}$, no Brasil, $96 \%$ dos jovens de 18 a 35 anos acessam essa plataforma todos os dias, sua preferencia é maior que a TV a cabo. Ainda de acordo com esse relatório, $31 \%$ dos usuários procuram a plataforma para acessar conteúdo de aprendizado. Como descreve Costa (2014) o uso do vídeo para esse fim cresce cada vez mais devido a sua aprendizagem dinâmica e por ser um canal que facilita ocasionais contestações.

Apesar do número de jovens que atualmente vem fazendo sucesso nessa plataforma (os youtubers) a partir da produção de seus vídeos, os alunos da nossa escola nunca os tinham produzido e alguns acreditavam que ele não poderia ser utilizado como uma ferramenta para aprender. Assim, a produção do vídeo foi um desafio para esses alunos.

No início eles tiveram dificuldades no planejamento. Para superar essas dificuldades, os alunos procuraram informações na web de como produzir um vídeo. Depois de estudarem essas informações e tirarem dúvidas com as professoras, deram início a produção de seus vídeos e durante essa construção, nas aulas teóricas foram esclarecendo dúvidas e mostrando textos produzidos por eles sobre o conteúdo.

Antes dessa construção, os alunos apresentaram dúvidas sobre alguns conceitos como agente redutor e agente oxidante e determinação do número de oxidação. Antes de esclarecer a essa dúvida solicitamos que os alunos realizassem uma pesquisa em livros didáticos e artigos científicos e trouxessem para a aula. Todos trouxeram resumos de suas pesquisas com os conceitos acima e juntos fomos discutindo cada um. Peruzzo e Canto (2016) definem agente redutor como a espécie química que age provocando a redução de

\footnotetext{
${ }^{1}$ https://www.thinkwithgoogle.com/intl/pt-br/youtubeinsights/2017/introducao/
} 
algum elemento presente nos reagentes e o agente oxidante como aquele que provoca a oxidação de algum elemento presente nos reagentes.

Após essa etapa, eles iniciaram a construção do vídeo e neles conseguiram explicar algumas reações. A figura 1 ( $\mathrm{a}$ e b) mostra um aluno explicando em seu vídeo duas reações de oxirredução.
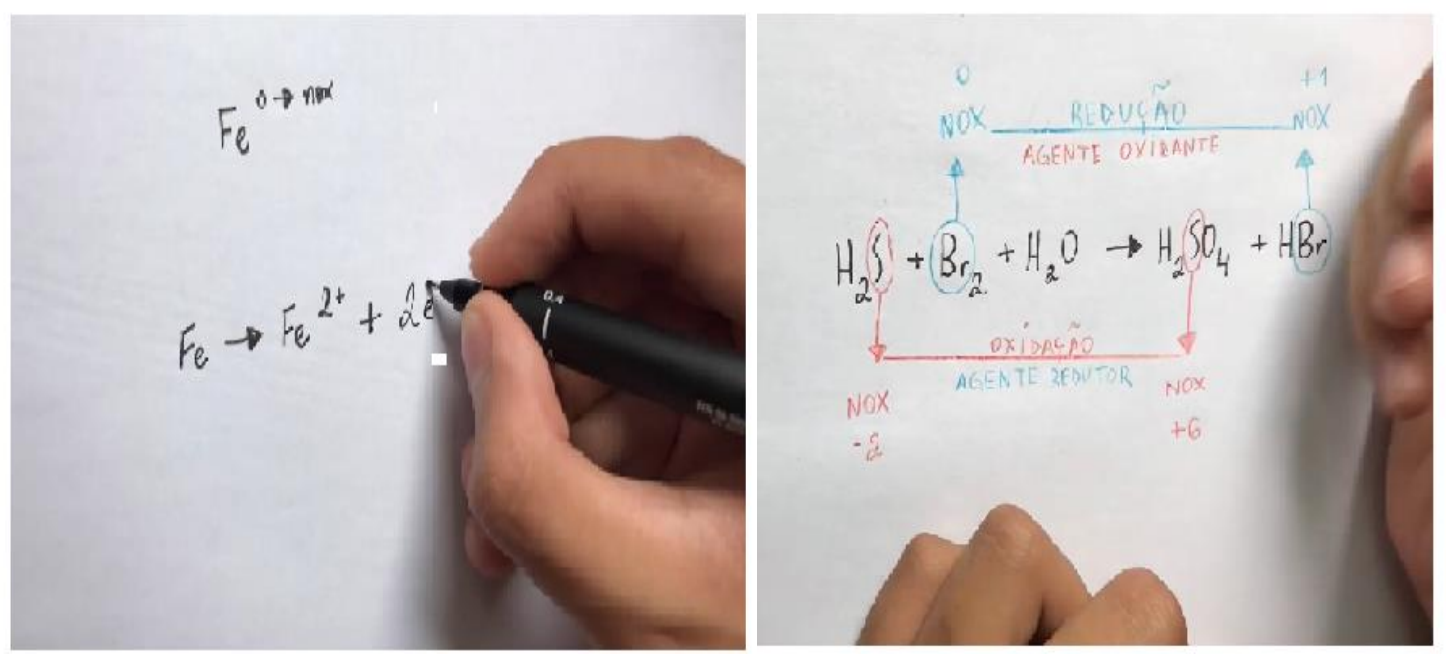

Figura 1 - Aluno explicando a equação de oxidação do ferro e b) o aluno mostrando os agentes oxidantes e redutores na equação. Fonte: as autoras.

Um grupo utilizou o desenho de uma maçã (Figura 2) em seu vídeo para explicar o processo de oxidação.

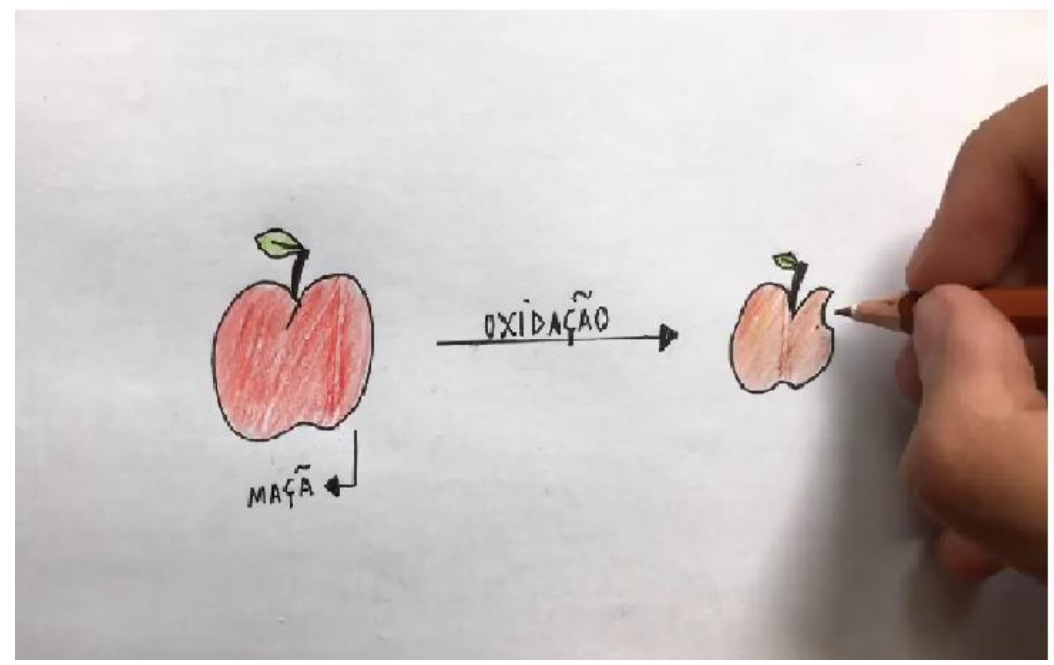

Figura 2 - Demonstração de oxidação a partir de um desenho.

Fonte: as autoras.

Para explicar seu desenho, o aluno descreveu de forma simples que quando a maçã é cortada é liberada uma substância que ao entrar em contato com o $\mathrm{O}_{2}$ presente no ar sofre oxidação. Nesse momento alguns alunos perguntaram quem era o agente redutor e o oxidante nesse exemplo. $O$ grupo explicou que a substância liberada pela maçã era $o$ agente redutor e o agente oxidante era $\mathrm{o} \mathrm{O}_{2}$. Esse resultado evidencia que o grupo entendeu os conceitos de agente redutor e agente oxidante. 
Como descrito anteriormente, cada grupo realizou um experimento em seu vídeo de baixo custo e apresentou para a classe. Um dos experimentos escolhido pelos alunos foi a oxidação da palha de aço. O quadro 1 mostra os materiais de baixo custo e o procedimento utilizados nesse experimento.

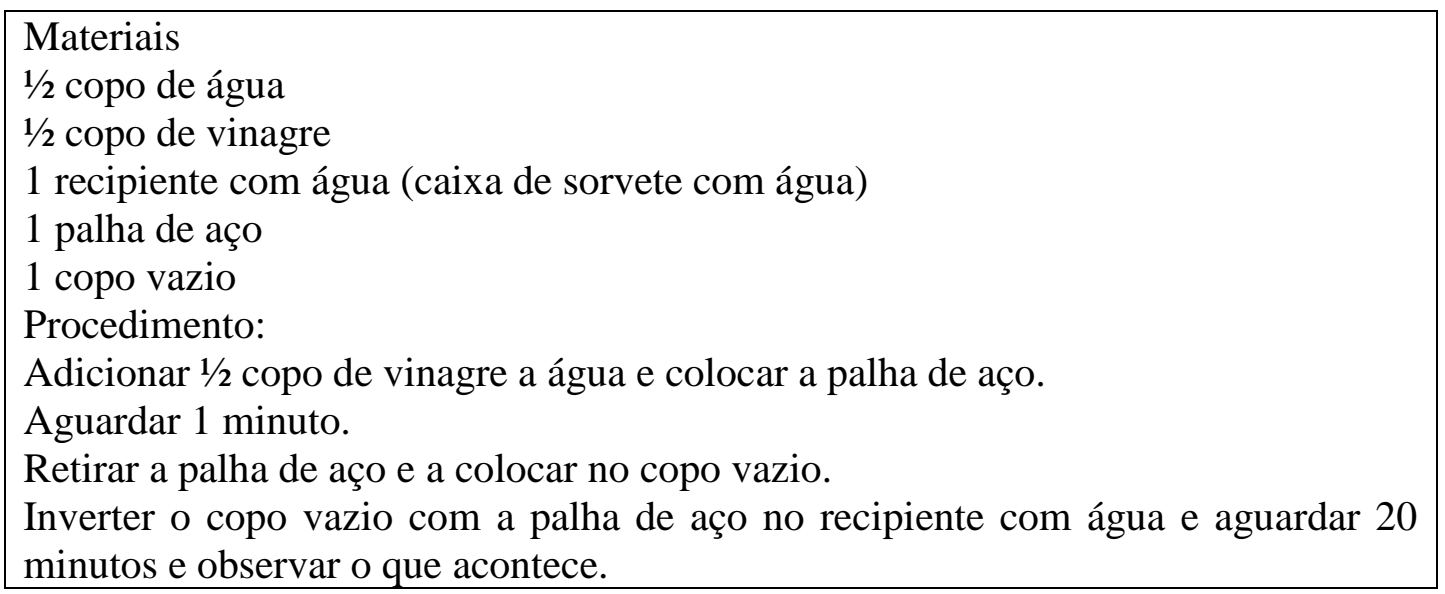

Quadro 1 - Materiais e procedimento utilizados pelo grupo.

A figura 3 mostra como ficou a palha de aço após o experimento.

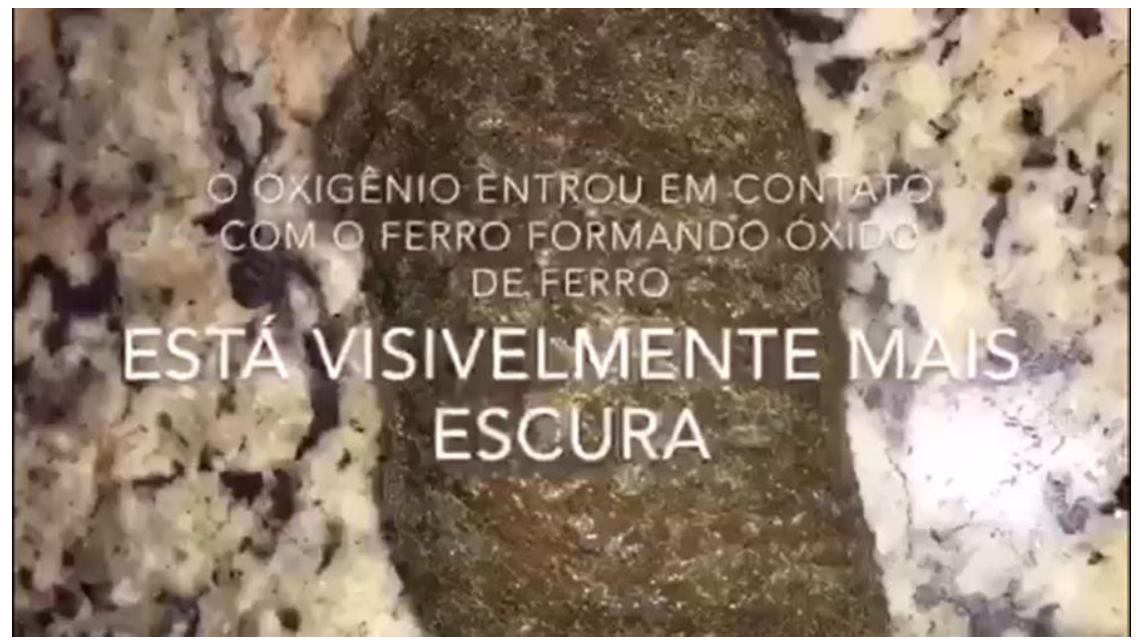

Figura 3 - Oxidação da palha de aço apresentado pelo grupo.

Fonte: as autoras.

Embora o experimento realizado pelos alunos seja muito comum na literatura, acreditamos que o objetivo da proposta foi alcançado, pois o que queríamos avaliar era o desempenho do aluno no desenvolvimento do experimento envolvendo o fenômeno de oxirredução e a interpretação das observações e os alunos conseguiram explicar os resultados obtidos. Os mesmos resultados foram observados nos outros grupos.

Outro item solicitado para ser apresentado no vídeo foi a resolução de um exercício proposto por eles. A figura 4 mostra um dos exercícios escolhido por um grupo para determinar os números de oxidação das espécies envolvidas na reação, o agente redutor e o agente oxidante. 


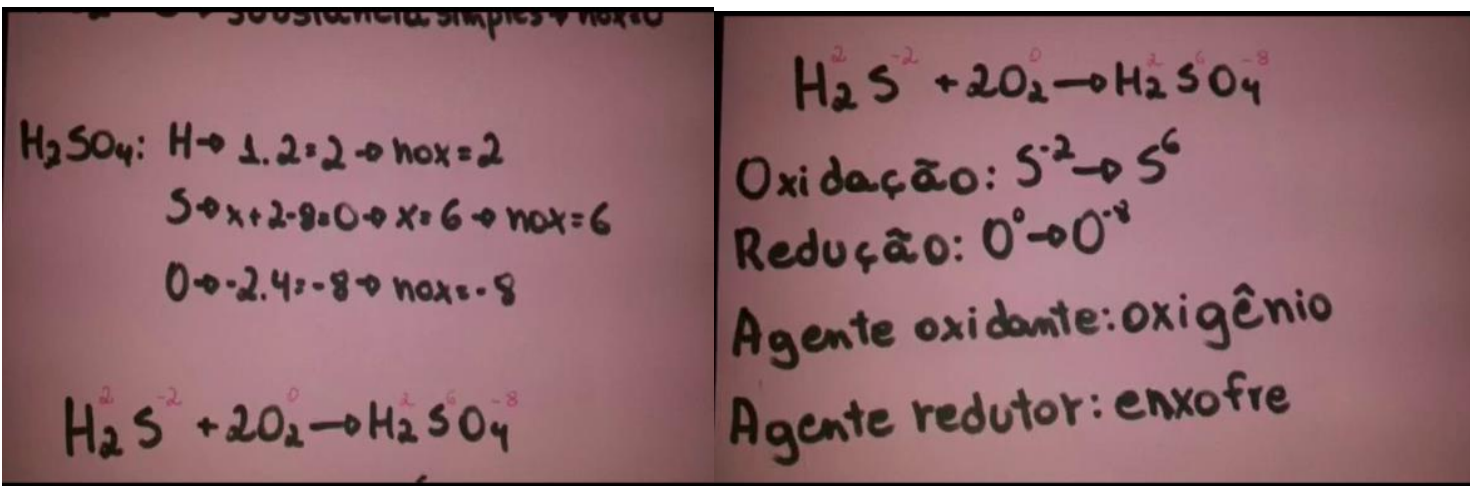

Figura 4 - Resolução do exercício por um grupo.

Fonte: as autoras.

Durante a apresentação dos vídeos observamos um entusiasmo e ansiedade por parte dos grupos. Houve trocas de ideias e comentários sobre exemplos de oxidação no dia a dia com o escurecimento da prata (talheres ou joias) quando reage com o oxigênio, a ferrugem que ocorre pela ação do oxigênio em metais (os alunos mencionaram a corrente da bicicleta e os portões) e a ação da vitamina $\mathrm{C}$ como antioxidante em nosso organismo.

Assistir a apresentação dos grupos foi gratificante pois evidenciamos que a produção dos vídeos levou os alunos a uma maior interação com seus colegas favorecendo a socialização das ideias entre os membros dos grupos e os auxiliou a ouvir e respeitar opiniões diferentes das suas e em alguns momentos a negociar e/ou renunciar as próprias ideias. Essa socialização é importante no processo de aprendizagem, pois como descreve Vygotsky (1989) a aprendizagem é uma experiência social, de interação pela linguagem e pela ação.

Ao final da apresentação, os alunos avaliaram a contribuição dos vídeos na sua aprendizagem. Algumas respostas estão apresentadas abaixo:

"Foi uma forma bem interessante e dinâmica de compreender melhor a matéria";

"Com as aulas, exercícios e esta atividade, pude entender melhor o processo de oxirredução e como ele funciona. E descobri que a melhor maneira de aprender é ensinando."

"Através dessa atividade pude desenvolver mais o meu conhecimento com relação as reações de oxirredução.",

"Foi um trabalho onde aprendi bastante, realiza-lo tornou a matéria ainda mais fácil de forma divertida e criativa."

"Realizar o experimento em grupo e discuti-la facilitou a compreensão da matéria."

"Acrescentou uma gama de conhecimentos sobre o tema abordado."

"Aprendi muito, o vídeo me interagiu e senti que junto com as aulas e a explicação nunca me farão esquecer o conteúdo."

Essas respostas demonstram que os alunos se interessam pelo uso de multimídias para sua aprendizagem e que a produção do vídeo contribuiu para a aprendizagem do conteúdo de oxirredução.

Essas mesmas percepções foram encontradas por Vickery (2016) quando realizou uma avaliação da utilização de vídeo com seus alunos. Seus resultados mostraram que os alunos estão cada vez mais se interessando por mídias digitais, pois é algo sem dificuldades para eles. Ao mesmo tempo, essa autora enfatiza que a aprendizagem virá decorrente da discussão entre os grupos e não somente da criação digital. 
Vickery (2016) também descreve que em um trabalho com vídeo é importante que o professor incentive seu aluno a perceber que seu esforço foi bem sucedido a partir da sua autoavaliação. Isso é necessário para que o aluno reconheça que ele construiu sua aprendizagem, ou seja, não foi somente um receptor da informação do conteúdo.

Tomando como referência essa recomendação de Vickery, nesse trabalho os alunos realizaram uma autoavaliação da sua aprendizagem respondendo a questão: Como você avalia sua aprendizagem a partir da construção do seu vídeo? Para responder a essa questão sugerimos 4 conceitos: Muito bom, bom, regular e insatisfatório. Os resultados mostraram que 37 alunos consideraram sua aprendizagem muito boa, 5 consideraram boa e 3 regular. Esses resultados evidenciam que os alunos perceberam a contribuição do vídeo na sua aprendizagem de oxirredução.

\section{CONCLUSÃO}

Os resultados dessa experiência evidenciaram que a produção do vídeo é um recurso didático que contribui para aprendizagem potencialmente significativa de oxirredução. Essa ferramenta também estimulou a participação dos alunos na atividade, conduzindo a sua predisposição para a aprendizagem do conteúdo proposto, além de estimular o trabalho em equipe, desenvolvendo assim, a socialização de ideias.

\section{REFERÊNCIAS}

AMARAL, L. H; AMARAL, C. L. C. Tecnologias de comunicação aplicadas à educação. In: MARQUESI, S.C.; ELIAS, V.M.S.; CABRAL, A.L.T. (Org). Interações Virtuais: Perspectivas para o ensino de língua portuguesa à distância. São Carlos: Claraluz, 2008.

COSTA, I. Novas Tecnologias e Aprendizagem. 2.ed. Rio de Janeiro: Wak Editora, 2014.

LIMA, A. A. O uso do vídeo como um instrumento didático e educativo: um estudo de caso do CEFET-RN. Florianópolis, 140f. Dissertação (Mestrado em Engenharia de produção) - Programa de Pós- Graduação em Engenharia de Produção. UFSC, 2001.

MOORE, J. Química para Leigos. Rio de Janeiro: Alta Books, 2010.

MORAN, J.M. Vídeos são instrumentos de comunicação e de produção. Entrevista ao Jornal do Professor. 2009. Disponível em:

http://www.eca.usp.br/prof/moran/site/textos/tecnologias_eduacacao/videos.pdf.

Acesso:05/2018.

MOREIRA, M.A. Aprendizagem Significativa: a teoria e textos complementares. $1^{\mathrm{a}}$ ed. São Paulo: Editorial, 2012.

NAPOLITANO, M. Como usar o Cinema na Sala de Aula. São Paulo: Editora Contexto, 2004.

OLIVEIRA, A.R. Corrosão e tratamento de superfície. Belém: IFPA, 2012. 
PASSOU, A. S.; MELO, W. V.; ANDRADE, L.; PEREIRA, R. M. M. Fatores que influenciam na utilização de filmes como recurso didático pelos docentes de ciências. Atas do VIII Encontro Nacional de Pesquisa em Educação em Ciências - VIII ENPEC, Campinas, SP, 2011.

PERUZZO, F. M., CANTO, E. L. Química na Abordagem do Cotidiano. São Paulo: Saraiva, 2016.

SANTOS, E.; ALVES, L. Práticas pedagógicas e tecnologias digitais. Rio de Janeiro: E-papers, 2006.

SILVA, J. L. et al. A utilização de vídeos didáticos nas aulas de química do Ensino Médio para abordagem histórica e contextualizada do tema vidros. Química Nova na Escola, v.34, n.4, p.189-200, nov.2012.

VICKERY, A. et al. Aprendizagem ativa nos anos iniciais do ensino fundamental. Porto Alegre: Penso, 2016.

VYGOTSKY, L. S. A formação social da mente. São Paulo: Martins Fontes Editora LTDA, 1989. 